\title{
Stressors identified by caregivers for veterans with Parkinson's disease
}

\author{
Naomi D. Nelson ${ }^{1}$, Linda R. Fincher ${ }^{1}$, Shawna L. Johnson ${ }^{1,2}$, Eugene C. Lai ${ }^{1,3}$ \\ 1. Parkinson's Disease Research, Education, and Clinical Center, Michael E. DeBakey VA Medical Center, Houston, TX, \\ United States. 2. Galveston VA Outpatient Clinic Galveston, TX, United States. 3. Weill Cornell Medical College, Houston \\ Methodist Neurological Institute, Houston, TX, United States.
}

Correspondence: Naomi D. Nelson. Address: 2128 Colquitt St. Houston, TX, United States.

Email: Naominelson29@gmail.com

Received: October 31, 2013

Accepted: February 12, 2014

Online Published: March 7, 2014

DOI : $10.5430 /$ cns.v2n2p84

URL: http://dx.doi.org/10.5430/cns.v2n2p84

\section{Abstract}

Nurses assume that they know the stressors of Parkinson's disease (PD) caregivers but a scarcity of research findings exists. This study was designed to identify those needs and stressors for the purposes of improving support and developing caregiver educational and interventional programs.

Caregivers were recruited from a database of 756 U.S. veterans with PD. A caregiver questionnaire was mailed to a random sample of 300 subjects. Non-parametric statistics were used to interpret caregiver characteristics and variable correlations. A logistic regression model provided insight into factors influencing stress.

One hundred and fifteen caregivers participated (38.3\% response). Their mean age was 66.6 years. Eighty-four percent had been a caregiver between 3-20 years, and 50 percent estimated a PD disease severity above 7 (0-10 scale).

We learned that as PD progresses in severity and requires more physical and emotional support, nurses need to attend to caregivers' increased stressors and quality of life.

\section{Key words}

Caregiving, Stress, Exploratory research, Parkinson's disease, Veterans

\section{I ntroduction}

Parkinson's disease (PD) extracts substantial burden on patients, their families, and health care resources primarily through a complex and lengthy disease course. The relationships among the veterans and family members are affected early in the disease process and as the disease advances, the family caregivers increasingly assume a multitude of daily tasks that become as essential to the patient's well-being as other treatment methods ${ }^{[1-3]}$. Nurses relate to these PD caregivers on a regular basis and make assumptions about their stressors and needs often without the advantage of subjective information that would promote individualized care. This study was designed to explore the stressors and illness factors that are perceived by caregivers for patients with PD, and to plan nursing education and interventions based on those findings. 


\section{Background and literature review}

Parkinson's disease (PD) is chronic, progressive, and disabling. Clinical characteristics of PD include motor features (tremor at rest, rigidity, bradykinesia, and postural instability) and non-motor features (autonomic dysfunction, cognitive and neurobehavioral abnormalities, and sensory and sleep problems) ${ }^{[4,5]}$. The uncertain trajectory of the illness, the advancing age of the patient and the degenerative progression of the symptoms contribute to increased stress and strain for the caregivers and those for whom they care ${ }^{[6-8]}$.

Caregiver stress is a term frequently used in the literature when discussing caring for children and adults who live with chronic conditions that are usually accompanied by downward trajectories. The theoretical definitions of caregiver stress, and common concepts of burden, strain, and distress are confusing and complex ${ }^{[1,9]}$, but are usually based on the biopsychosocial effects of caring for a relative or friend which exceed the caregiver's coping resources ${ }^{[10]}$.

Although nineteen percent of all U.S. caregivers provide care for those living with a neurological disorder, including $\mathrm{PD}^{[11]}$, less than one percent of published PD international journal papers refers to caregiving issues ${ }^{[11]}$. These studies, primarily cross-sectional, involved PD caregivers of non-veterans and reported a myriad of responses to caregiving. The responses included increased caregiver stress ${ }^{[6,12,13]}$; tiredness and fatigue ${ }^{[7]}$; sleep disturbances ${ }^{[12,14,15]}$; physical burden ${ }^{[16]}$; psychological burden ${ }^{[17,18]}$; changes in relationships ${ }^{[15,19-23]}$; decline in health-status ${ }^{[7,20]}$; mental health changes ${ }^{[23,24]}$; and loss of independence ${ }^{[17]}$.

Due to the complexity of factors, PD caregiver stress has unique manifestations when compared with caregivers of patients with other neurological conditions, specifically multiple sclerosis ${ }^{[25]}$ and Alzheimer's disease ${ }^{[22]}$. Some of these stressors are related to those cited above, but more specifically, a decline in the quality of the relationship and progressive physical impairment of the patient ${ }^{[25]}$ are reported as particularly important in $\mathrm{PD}^{[21,22,25,26]}$.

Research studies involving caregivers for veterans have been limited until the National Alliance on Caregiving (NAC) conducted a study comparing caregivers for veterans $(n=462)$ with national caregivers $(n=1,307){ }^{[27]}$. Selected findings are described as follows. More than $60 \%$ of the veterans had served during the Viet Nam War or earlier ${ }^{[27]}$. More than 40 hours a week spent in caregiver functions were reported by veterans' caregivers (43\%) compared to the national sample of caregivers $(13 \%){ }^{[27]}$. Twice as many veterans' caregivers $(30 \%)$ had been caregiving for 10 years or more compared to $15 \%$ of the national caregivers ${ }^{[27]}$. More than twice as many veteran caregivers $(68 \%)$ reported their situation as highly stressful compared to $31 \%$ of the national group ${ }^{[27]}$. Those who reported higher stress levels tended to be older and were more likely to be spouses ${ }^{[27]}$. Eight-two percent of the veterans' caregivers did not receive respite services from the VA or other organizations ${ }^{[27]}$.

Although the above findings are informative and provide much needed information about caregiving for veterans, minimal data are known about the stressors facing caregivers of veterans with a specific condition such as Parkinson's disease. These facts provide a strong rationale for conducting this type of exploratory study. Only one study at the time of this project ${ }^{[1]}$ had been published about caregivers for U.S. veterans with PD, and in that study, which used standardized measures to ascertain caregiver distress, the authors supported the need for further research that focused on veteran caregiver assessment and self-reports of caregiver characteristics and burdens ${ }^{[1]}$.

Demographic characteristics of veterans lend further support for this study ${ }^{[29]}$. According to the United States Government Department of Veteran Affairs, over 37\% of the veteran population is over the age of 65 compared with $13 \%$ of the general population, and these numbers of the eldest cohorts are expected to increase the need for geriatric services and all forms of long-term care ${ }^{[29]}$. The demand for care of veterans increases significantly with an aging population and particularly those with chronic, progressive illnesses. Older veterans have a higher percentage of functional limitations, problems with activities of daily living, and a greater likelihood of having a disability than non-veterans ${ }^{[29,30]}$. Veterans also typically live 
with several comorbid chronic conditions that may complicate the caregiving experience ${ }^{[31]}$. In one study of over 4,000 veterans, most of them over the age of 65 years, the average number of comorbid conditions was $6.3^{[32]}$.

The United States Veteran Health Administration, through its medical centers and clinics, treats over 45,000 veterans with PD each year with six funded VA sites providing a network for more specialized care for patients with PD and their caregivers ${ }^{[33]}$. These Parkinson's Disease Research, Education and Clinical Centers (PADRECC's) offer a distinctive opportunity to study the progressive changes in the patients and to enhance the knowledge about patient care and their caregivers. The PADRECC's are noted for their specialization and expertise in diagnosis and treatment of movement disorders, but the experience of the caregivers has not been specifically addressed.

The data and research findings cited above directed the researchers to design this study with the intent of identifying stressors perceived by caregivers for veterans with PD. The findings supported further planning and implementation of individualized nursing interventions and education.

The objectives of this exploratory study were: 1) to identify the stress levels of caregivers for veterans with PD, 2) to describe which illness factors of PD contributed to the caregiver stress, and 3) to specify the psychosocial and demographic features of those caring for veterans with PD.

\section{Methods}

\subsection{Design and sample}

Potential participants for this cross-sectional caregiver questionnaire were randomly recruited from an alphabetized database listing of 756 veterans diagnosed with Parkinson's disease and who were being followed longitudinally on a continuing basis in the PD Center. A random sample of 300 veterans was mailed a preliminary letter informing them about the forthcoming caregiver questionnaire and asking them to identify a person whom they considered their caregiver. The veterans were encouraged to contact the investigators if they had any questions about the selection of the caregiver. A caregiver was defined as a non-agency individual who assisted the patient (even occasionally) with preparing meals, bathing or dressing, transportation, and/or providing emotional support either at home or in a nursing facility. The ability to read English was a requirement for participation in the study.

Three weeks after the initial letter, the veteran was mailed the questionnaire in a packet with a stamped, self-addressed envelope for the identified caregiver to complete and return; 115 caregivers returned the completed questionnaires between October 2010 and January 2011. Thirty-five questionnaires were returned and not used due to the patient's death, incorrect address, or a diagnosis other than PD. Using the same original alphabetical database, the questionnaire was sent to the next 35 randomly listed veterans.

By returning the questionnaires, the subjects were giving consent to be included in the study. Approval for the study was granted by the Michael E. DeBakey VA Medical Center Research and Development Committee and the Baylor College of Medicine Institutional Review Board.

\subsection{Measures}

After a review of validated PD caregiving instruments ${ }^{[1,15,18,20]}$, the researchers found none that integrated all the required components for this study. The preferred survey was one devised for a mailed caregiver study, contained specific questions unique to this sample of participants, and was simple and short in design so that caregivers would be more likely to complete the questionnaire. Most importantly, it needed to be appropriated for caregivers of veterans with PD. Based on these findings, a self-report 25 -item caregiver questionnaire was designed by the researchers. The items were selected by the investigators after a review of the literature and by input from caregivers who identified areas of concern at PD 
conferences, support groups, and counseling sessions. Items chosen for inclusion were the veteran's gender and age, demographic data for the caregiver (age, income, gender, work, education, employment, marital status, living arrangements, and relationship to the veteran), caregiver characteristics (health, quality of life, length of time spent in caregiving role, stress and comfort levels in caregiving, and perceived social support). Demographic and caregiver characteristics are listed in Table 1.

Table 1. Caregiver characteristics

\begin{tabular}{ll}
\hline Variables & $\mathbf{n}(\%)$ \\
\hline $\begin{array}{l}\text { Gender (n=115) } \\
\text { Men }\end{array}$ & $6(5)$ \\
Women & $109(95)$ \\
Age (n=115) Range 23-88 years & \\
$<30$ & $1(1)$ \\
$31-45$ & $4(3)$ \\
$46-60$ & $27(23)$ \\
$61-75$ & $53(46)$ \\
$76-90$ & $30(26)$
\end{tabular}

\section{Ethnic Background (n=111)}

Caucasian

African-American

Hispanic

$8(7)$

Other

$6(5)$

\section{Education (n=115)}

Completed High School or less

Some college

Baccalaureate or graduate degree

Marital Status of Caregiver $(\mathbf{n}=115)$

Married

$104(90)$

Divorced/separated

Widowed/never married

4 (4)

Relationship to the Veteran $(n=112)$

Spouse

Adult Child

Other (relative/friend)

\section{Living Arrangements (n=113)}

With the Veteran who has PD

With other family/friends

Alone

7 ( 6$)$

Employment (Presently working $\mathbf{n}=(\mathbf{1 1 1})$

Yes

No

$74(67)$ 
Table 1. (Continued.)

\begin{tabular}{|c|c|}
\hline Variables & $\mathbf{n}(\%)$ \\
\hline \multicolumn{2}{|l|}{ Reasons for not Working (n=56) } \\
\hline Retirement & $30(54)$ \\
\hline Caregiving responsibilities & $19(34)$ \\
\hline Never worked outside the home & $4(7)$ \\
\hline Health problems & $3(5)$ \\
\hline \multicolumn{2}{|l|}{ Adequacy of Current Income (n=110) } \\
\hline Less than adequate & $35(32)$ \\
\hline Adequate & $66(60)$ \\
\hline More than adequate & $9(8)$ \\
\hline \multicolumn{2}{|l|}{ Current State of Health $(n=114)$} \\
\hline Poor & $6(5)$ \\
\hline Fair & $30(26)$ \\
\hline Good & $63(55)$ \\
\hline Excellent & $15(13)$ \\
\hline \multicolumn{2}{|l|}{ Quality of Life (n=115) } \\
\hline Not good & $5(4)$ \\
\hline Sometimes good & $23(20)$ \\
\hline Usually good & $77(67)$ \\
\hline Life couldn't be better & $10(9)$ \\
\hline \multicolumn{2}{|l|}{ Adequacy of Physical Help (n=98) } \\
\hline More than adequate & $17(17)$ \\
\hline Adequate & $38(39)$ \\
\hline Less than adequate & $43(44)$ \\
\hline \multicolumn{2}{|l|}{ Adequacy of Emotional Help (n=109) } \\
\hline More than adequate & $25(23)$ \\
\hline Adequate & $59(54)$ \\
\hline Less than adequate & $25(23)$ \\
\hline \multicolumn{2}{|c|}{ Attendance at Support Groups $(\mathrm{n}=\mathbf{1 0 0})$} \\
\hline Never attended & $74(74)$ \\
\hline Attend once a week & $5(5)$ \\
\hline Attend once a month & $10(10)$ \\
\hline Attend several times a year & $11(11)$ \\
\hline
\end{tabular}

Prescreening of the questionnaire was conducted with six health care professionals who had experience with patients and caregivers and who had participated in PD research survey projects. One item was omitted due to confusion in answering the question. The majority items were Likert-type where subjects marked or circled the best response. Single-item and open-ended measures were chosen for health, stress, and quality of life; these measures are similarly referenced in other studies ${ }^{[34-36]}$. Several items requested multiple responses and four items requested a write-in response specific to clinical and educational ideas for our PADRECC. Levels of stress were selected as the outcome variable and for purposes of this 
study, we combined the answers into three groups: those reporting less stress (low stress), those reporting a mid-range of stress (medium stress), and those reporting more severe stress (high stress). Single-item measures were chosen for assessments of health, status, and quality of life. Several open-ended questions assessed support group participation and suggestions for improving care in the clinic.

Table 2. Specifics related to parkinson's care

\begin{tabular}{|c|c|}
\hline Variables & n(\%) \\
\hline \multicolumn{2}{|l|}{ Quality of Life with Patient (n=111) } \\
\hline Usually good, couldn't be better & $90(81)$ \\
\hline Not good, sometimes good & 21(19) \\
\hline \multicolumn{2}{|l|}{ Estimate Severity of PD (n=112) } \\
\hline Minimal symptoms & $17(15)$ \\
\hline Moderate symptoms & $58(52)$ \\
\hline Severe symptoms & $37(33)$ \\
\hline \multicolumn{2}{|l|}{ Estimate Length of Time of PD $(n=113)$} \\
\hline Less than 5 years & $37(33)$ \\
\hline $6-10$ years & $64(57)$ \\
\hline $11-<20$ years & $12(11)$ \\
\hline \multicolumn{2}{|l|}{ Daily Hours Spent in Caregiving $(n=106)$} \\
\hline Less than 3 hours/day & $49(46)$ \\
\hline 4-9 hours/day & $38(36)$ \\
\hline More than 9 hours/day & 19(18) \\
\hline \multicolumn{2}{|l|}{ Length of Time Providing Care $(n=109)$} \\
\hline Less than 3 years & $15(14)$ \\
\hline $3-10$ years & $61(56)$ \\
\hline $11-<20$ years & $33(30)$ \\
\hline \multicolumn{2}{|l|}{ Levels of Stress $(n=110)$} \\
\hline Low & $32(29)$ \\
\hline Medium & $43(39)$ \\
\hline High & $35(32)$ \\
\hline \multicolumn{2}{|l|}{$\begin{array}{l}\text { Reasons for Not Attending Support Groups }(n=111)>\text { one } \\
\text { answer }\end{array}$} \\
\hline Distance & $27(24)$ \\
\hline Didn't know about them & $22(20)$ \\
\hline Too many caregiving responsibilities & $40(36)$ \\
\hline No transportation & $8(7)$ \\
\hline Not interested/Too discouraging & $14(13)$ \\
\hline Other reasons & $6(5)$ \\
\hline Major Caregiving Challenges & Rank (Order of Importance) \\
\hline Safety concerns (driving, falls, medications) & 1 (most) \\
\hline Motor problems (tremors, freezing, dyskinesias) & 2 (mid-range) \\
\hline Assistance with personal care (feeding, dressing, hygiene) & 3 (least) \\
\hline
\end{tabular}


Because of the exploratory nature of this study and an absence of PD caregiving measures specific for veterans, content validity was established, but more advanced validity and reliability data were not determined.

Table 3. Intercorrelations of stress with psychosocial and illness factors

\begin{tabular}{|c|c|c|c|c|c|c|c|c|c|c|c|}
\hline Variables & Stress & $\begin{array}{l}\text { Severity } \\
\text { of PD }\end{array}$ & $\begin{array}{l}\text { CG } \\
\text { Length }\end{array}$ & $\begin{array}{l}\text { Hrs. of } \\
\text { CG }\end{array}$ & $\begin{array}{l}\text { Age of } \\
\text { CG }\end{array}$ & $\begin{array}{l}\text { Age of } \\
\text { Vet. }\end{array}$ & $\begin{array}{l}\text { Health } \\
\text { of CG }\end{array}$ & $\begin{array}{l}\text { QOL } \\
\text { of CG }\end{array}$ & QOR & $\begin{array}{l}\text { Comfort } \\
\text { in CG } \\
\text { Role }\end{array}$ & $\begin{array}{l}\text { Income } \\
\text { of CG }\end{array}$ \\
\hline \multicolumn{12}{|l|}{ Stress $(n=115)$} \\
\hline $\begin{array}{l}\text { Severity of } P D^{a} \\
(n=114)\end{array}$ & $.394^{\mathrm{a}}$ & ---- & & & & & & & & & \\
\hline $\begin{array}{l}\text { CG Length }{ }^{b} \\
(n=108)\end{array}$ & .189 & .181 & ---- & & & & & & & & \\
\hline $\begin{array}{l}\text { Hours of } \\
\text { CG/day } \\
(n=106)\end{array}$ & $.334^{\mathrm{a}}$ & $.318^{\mathrm{a}}$ & $.313^{\mathrm{a}}$ & ---- & & & & & & & \\
\hline $\begin{array}{l}\text { Age of } \\
C G(n=115)\end{array}$ & -.022 & .018 & .266 & .053 & ---- & & & & & & \\
\hline $\begin{array}{l}\text { Age of } \\
\text { Vet. }(n=114)\end{array}$ & -.012 & -.033 & .154 & .133 & $.618^{\mathrm{a}}$ & ---- & & & & & \\
\hline $\begin{array}{l}\text { Health of CG } \\
(n=115)\end{array}$ & -.164 & -.227 & $-.212^{b}$ & -.095 & -.086 & .081 & ---- & & & & \\
\hline $\begin{array}{l}\text { Quality of Life } \\
\text { of CG (QOL) } \\
(n=115)\end{array}$ & $-.247^{\mathrm{a}}$ & $-.246^{\mathrm{a}}$ & -.172 & $-.211^{b}$ & $-.195^{b}$ & -.064 & $.616^{\mathrm{a}}$ & ---- & & & \\
\hline $\begin{array}{l}\text { Quality of } \\
\text { Relationship } \\
\text { (QOR) }(n=111)\end{array}$ & $-.253^{\mathrm{a}}$ & $-.294^{\mathrm{a}}$ & -.085 & -.058 & -.061 & -.044 & $.276^{\mathrm{a}}$ & $.394^{\mathrm{a}}$ & ---- & & \\
\hline $\begin{array}{l}\text { Comfort in CG } \\
\text { Role } \\
(\mathrm{n}=111)\end{array}$ & $-.231^{b}$ & -.105 & .106 & .141 & -.029 & .078 & $.199^{b}$ & $.296^{\mathrm{a}}$ & $.250^{\mathrm{a}}$ & ---- & \\
\hline $\begin{array}{l}\text { Income of CG } \\
(n=111)\end{array}$ & -.147 & $-.235^{\mathrm{b}}$ & -.045 & $-.255^{\mathrm{a}}$ & -.024 & .042 & $.386^{\mathrm{a}}$ & $.322^{\mathrm{a}}$ & .102 & .010 & ---- \\
\hline
\end{tabular}

Spearman's rho was used to capture the relation among variables.

${ }^{a}$ Correlation is significant at the 0.01 level (2-tailed).

${ }^{\mathrm{b}}$ Correlation is significant at the 0.05 level (2-tailed).

a refers to 0.01 significance, $b$ refers to 0.05 significance

\subsection{Data analysis}

Descriptive data were collected to interpret caregiver characteristics for all study measures. Spearman's rho was used to analyze the correlations among selected nonparametric variables of interest. This correlation coefficient was used because the data violated parametric assumptions such as non-normally distributed data ${ }^{[37]}$. To determine the strength of the independent variables and the probability of stress for the caregivers, a multinominal logistic regression model was 
employed using the default Forced Entry Method ${ }^{[37]}$. Multinominal logistic regression accepts non-normally distributed data and recommends three levels of measurement for the dependent variable. The omitted data appeared to be random without any systematic pattern; therefore, an exclude cases pair wise method was used for handling missing data. All psychometrics were obtained by using the applied statistical program - Predictive Analytics Software (PASW) Version 18 (formerly SPSS) ${ }^{[37]}$.

Table 4. Multinominal logistic regression for stress levels

\begin{tabular}{|c|c|c|c|c|c|c|}
\hline & & & & & 95\% CI for odds ratio & \\
\hline Stress $^{\text {a }}$ (Low) & B & Std. error & Sig. & Lower & Odds ratio & Upper \\
\hline \multicolumn{7}{|l|}{ 2.00 Medium vs. Low } \\
\hline \multicolumn{7}{|l|}{ Stress } \\
\hline Intercept & 3.783 & 2.689 & .159 & & & \\
\hline Age of Veteran & 1.204 & .668 & .072 & .900 & 3.333 & 12.348 \\
\hline Severity of PD ${ }^{b}$ & .843 & .506 & .095 & .862 & 2.324 & 6.266 \\
\hline Quality of Relationship & -1.541 & 1.137 & .175 & .023 & .214 & 1.988 \\
\hline Comfort in $\mathrm{CG}^{\mathrm{c}}$ Role & -1.627 & .677 & .016 & .052 & .197 & .741 \\
\hline Adequacy of Income & -.086 & .257 & .737 & .555 & .917 & 1.517 \\
\hline No. of CG Hrs./day & .968 & .484 & .046 & 1.018 & 2.632 & 6.800 \\
\hline Age of CG & -.037 & .026 & .153 & .916 & .964 & 1.014 \\
\hline Length of CG & -.159 & .407 & .696 & .384 & .853 & 1.893 \\
\hline \multicolumn{7}{|l|}{$\begin{array}{l}\text { 3.00 High Stress vs. } \\
\text { Low Stress }\end{array}$} \\
\hline Intercept & 2.994 & 3.214 & .352 & & & \\
\hline Age of Veteran & 1.046 & .817 & .200 & .574 & 2.846 & 14.103 \\
\hline Severity of PD & 1.384 & .598 & .021 & 1.236 & 3.992 & 12.891 \\
\hline Quality of Relationship & -1.883 & 1.198 & .116 & .015 & .152 & 1.592 \\
\hline Comfort in CG Role & -2.190 & .772 & .005 & .025 & .112 & .508 \\
\hline Adequacy of Income & -1.046 & .529 & .048 & .125 & .351 & .991 \\
\hline No. of CG Hrs./day & 1.379 & .543 & .011 & 1.369 & 3.970 & 11.515 \\
\hline Age of CG & -.026 & .034 & .441 & .913 & .975 & 1.041 \\
\hline Length of CG & .260 & .448 & .561 & .539 & 1.297 & 3.119 \\
\hline
\end{tabular}

a The reference category is 1.00, b PD-Parkinson's Disease, c CG-Caregiver

\section{Results}

Thirty-eight percent (115/300) responded to the questionnaire ( $\mathrm{n}=115,109$ women and 6 men). Significant age differences were observed between caregivers (mean age 67 years) and the veterans (mean age-72 years) $(p<0.05)$. Eighty- three percent of the caregivers were spouses and $17 \%$ were adult children, other relatives, or friends. Approximately one-third reported a less than adequate income and the inability to work due to caregiving responsibilities. Health problems were identified as fair to poor by almost one-third of the respondents with the top three problems categorized as hypertension 
(44\%), cardiac/respiratory changes $(27 \%)$, and back problems $(20 \%)$. More detailed caregiver characteristics are presented in Table 1.

When the caregivers were asked to identify their three major patient care challenges, the most cited problems were: 1) safety concerns (driving, risk of falling and medication accuracy), 2) motor problems (tremors, freezing episodes, and dyskinesias), and 3) assistance with personal care (feeding, dressing, hygiene). Specifics related to Parkinson's care are illustrated in Table 2.

Stress levels were positively correlated with severity of illness $(r=.394, p<0.01)$, hours of care $(r=.334, p<0.01)$, and negatively correlated with QOL $(r=-.247, p<0.01)$, quality of relationship $(r=-.253, p<0.01)$, and comfort in caregiving role $(r=-.231, p<0.05)$. Severity of PD was positively correlated with hours of care $(r=.318, p<0.01)$, and negatively associated with QOL $(r=-.246, p<0.01)$, quality of relationship $(r=-.294, p<0.01)$, and income $(r=-235, p<0.05)$. The health of the caregiver was positively associated with quality of life $(r=.616, p<0.01)$, quality of relationship $(r=.276$, $p<0.01)$, and income $(r=.386, p<0.01)$ and comfort in caregiving role $(r=.199, p<0.05)$. Table 3 illustrates the correlation matrix for all variables.

The analysis using multinominal logistic regression demonstrated that for medium stress vs. low stress, the two significant predictor variables were hours of care (the more care -the more stress) and comfort in the caregiver role (less comfortmore stress) (both $=p<0.05$ ). For high stress vs. low stress, the significant variables were severity of illness, hours of care, and a negative association with comfort in the caregiver role (all $=p<0.05$ ). Quality of life and quality of relationship reached a correlation coefficient of $0.616(p<0.01)$; therefore, QOL was not entered into the logistic model. The other variables in the model were not statistically significant. (Table 4 lists the results for the multinominal logistic regression procedure).

\section{Discussion}

This study examined the stressors reported by caregivers who provided care to aging veterans and who were living with progressive Parkinson's disease. The results indicated that caregivers assumed an important role in the management of patients with PD at all stages of the illness. This was a limited preliminary exploratory study, but our findings shared a resemblance to other results.

Significant stressors identified in this study, specifically the patient's severity of illness, length of disease, and hours of caregiving, were similarly reported in other PD research studies as major stressors for caregivers ${ }^{[14,15,24]}$. The caregiver study results indicated that the quality of the caregiver-veteran relationship was significantly related to stress levels; this finding was also supported by other researchers ${ }^{[1,20]}$. The duration of caregiving was predictably associated with daily hours spent in caregiving but not with stress levels. Quality of life was found to be significantly related to stress experiences with similar findings indicated in another seminal PD caregiving study ${ }^{[15]}$.

Additionally, the findings from this study provided information not frequently addressed with this special population of caregivers for veterans with PD. For example, the benefits of PD caregiver support groups are well documented ${ }^{[19]}$, but $74 \%$ of our respondents had never attended one (see Table 2) despite their availability in multiple locations of the city. The specific number of caregivers who attended support groups was not addressed in any other reviewed studies.

\section{Limitations}

Several limitations from this study may influence the interpretation of findings and the difficulty in generalizing the results to others who were not caregivers for veterans. This was a cross-sectional sample using a self-report questionnaire developed by the researchers. The non-responders were not studied and may have altered the findings by comparing differences between those who responded and those who did not. A longitudinal study, using standardized measures and 
including a control group, may have presented a more comprehensive look at causal relationships between caregiver stress and patient characteristics. It is also possible that a one-point in time study does not fully address the fluctuating nature of caregiving which is influenced by frequent physical and emotional changes.

This study may also have been enhanced by a more specific focus on the cognitive and behavioral changes of the patient and the mental health issues (i.e. depression) and physical functioning of the caregiver ${ }^{[38]}$, and to examine how these concerns affect stress levels. The majority of caregivers in this study were women caring for elderly veterans with PD and the results may not be as applicable in caring for younger veterans and for men who provide caregiving for women. As women age, they may experience daunting psychological and physical changes, such as reduced energy and strength, that may affect their ability to care for the patient and perform household tasks over a prolonged period of time. Future studies may choose to take into consideration younger patients of both genders, and to compare the responses of both men and women as caregivers.

\section{Application}

The results from this study have specifically directed the nurses from the PADRECC to develop strategic assessments and interventions that focus directly on the PD caregiver during their initial contact. The findings have encouraged the PADRECC-nurses to develop a strong partnership with caregivers in several ways: early identification of at-risk problems, frequent appraisal of caregiver stress throughout all stages of the illness, discussion of end-of-life issues earlier in the disease process [16], evaluation of changes in the health of caregivers and patients, and the use of several approaches when interacting with caregivers (educational programs, family meetings, and psychoeducational skill development) ${ }^{[39]}$.

The results of this study have also enabled the PADRECC nurses to suggest preventive measures for caregivers; specifically stress reduction techniques and individualized coping skills; referral to community resources, respite care, and social workers; introduction to self-management skills and counseling; and support for healthy living practices. The provision of support groups for PD caregivers has also been implemented at the VA and when distance is a concern, caregivers are encouraged to attend support groups in community locations. Other nursing initiatives that have been implemented in the PADRECC include on-line interactions oriented toward patient and caregiver concerns, and readily accessible 'coaching and support' in person and by telephone, during and following clinic visits.

The uncertain health trajectory for veterans diagnosed with PD and the prevalence of co-morbidities also provided a distinction to this study. The caregiving role and concomitant stressors may be influenced by these multiple health problems that require frequent ambulatory care clinic visits, often at distance from homes of veterans. Conversely, frequent clinic visits provide ongoing opportunities for observation of caregivers and patients and the development of trusting reciprocal relationships with the health care team.

\section{Conclusions}

In conclusion, this study highlighted the significant cooperation of veterans and their selected caregivers who contributed to understanding the question: "Who are the caregivers of veterans with PD and what are their special concerns?" Data from this study indicated that the severity of illness and hours of caregiving significantly influenced stress levels for caregivers.

This self-report exploratory questionnaire needs to be further validated with other instruments and analyzed with more established psychometric measures. The findings from this study could be used for future research that formulates appropriate measurement tools and research questions related to caregiving in PD (and other neurodegenerative conditions) for both non-veterans as well as veterans. Incorporating these research findings into the provision of clinical situations will strengthen the quality of care provided by nurses directed toward caregivers and patients living with chronic conditions. 


\section{Acknowledgement}

We are grateful for the time and efforts of the caregivers who participated in this study by completing the extensive self-report questionnaire. We also appreciate the cooperation of all the veterans with PD who helped in this study.

\section{References}

[1] Cifu DX, Carne W, Brown R, Pegg, P, Ong J, Qutubuddin A, Baron MS. Caregiver distress in Parkinsonism. Journal of Rehabilitation Research and Development. 2006; 43(4): 499-508. PMid:17123189 http://dx.doi.org/10.1682/JRRD.2005.08.1365

[2] Nelson ND. Psychosocial issues in Parkinson's disease. In: M Trail, EJ Protas, EC Lai (Eds.), Neurorehabilitation in Parkinson's disease: An evidence-based treatment model. Thorofare, NJ: Slack; 2006: 103-123.

[3] Leiknes I, Tysnes OB, Aarsland D, Larsen JP. Caregiver distress associated with neuropsychiatric problems in patients with Parkinson's disease: The Norwegian ParkWest study. Acta Neurologica Scandinavica. 2010; 122(6): 418-424. PMid:20175757 http://dx.doi.org/10.1111/j.1600-0404.2010.01332.x

[4] Hou JG, Lai EC. Overview of Parkinson's disease: Clinical features, diagnosis, and management. In: M Trail, EJ Protas, EC Lai (Eds.), Neurorehabilitation in Parkinson's disease: An evidence-based treatment model. Thorofare, NJ: Slack; $2006: 1$ 1-39.

[5] Nutt JG, Wooten GF. Diagnosis and initial management of Parkinson's disease. New England Journal of Medicine. 2005; 353: 1021-1027. PMid:16148287 http://dx.doi.org/10.1056/NEJMcp043908

[6] Calne SM. The psychosocial impact of late-stage Parkinson's disease. Journal of Neuroscience Nursing. 2003; 35(6): $306-313$. PMid:14713096 http://dx.doi.org/10.1097/01376517-200312000-00004

[7] Calne SM, Kumar A. Nursing care of patients with late-stage Parkinson's disease. Journal of Neuroscience Nursing. 2003; 35(5): 242-251. http://dx.doi.org/10.1097/01376517-200310000-00002

[8] Tan SB, Williams AF, Morris ME. Experiences of caregivers of people with Parkinson's disease in Singapore: A qualitative analysis. Journal of Clinical Nursing. 2012; 21(15-16): 2235-2246. PMid:22788558 http://dx.doi.org/10.1111/j.1365-2702.2012.04146.x

[9] Leggett AN, Zarit S, Taylor A, Galvin JE. Stress and burden among caregivers of patients with Lewy body dementia. The Gerontologist. 2011; 51(1): 76-85. PMid:20667944 http://dx.doi.org/10.1093/geront/gnq055

[10] Hunt CK. Concepts in caregiver research. Journal of Nursing Scholarship. 2003; 35(1): 27-32. PMid:12701523 http://dx.doi.org/10.1111/j.1547-5069.2003.00027.x

[11] Pasetti C, Rossi FS, Fornara R, Picco D, Foglia C, Galli J. Caregiving and Parkinson's disease. Neurological Science. 2003; 24(3): 203-204. PMid:14598088 http://dx.doi.org/10.1007/s10072-003-0131-1

[12] Happe S, Berger K. The association between caregiver burden and sleep disturbances in partners of patients with Parkinson's disease. Age and Ageing. 2002; 31(5): 349-354. http://dx.doi.org/10.1093/ageing/31.5.349

[13] Peters M, Fitzpatrick R, Doll H, Playford D, Jenkinson C. Does self- reported well-being of patients with Parkinson's disease influence caregiver strain and quality of life? Parkinsonism and Related Disorders. 2011; 17(5): 348-352. PMid:21356603 http://dx.doi.org/10.1016/j.parkreldis.2011.02.009

[14] Caap-Ahlgren M, Dehlin O. Factors of importance to the caregiver burden experienced by family caregivers of Parkinson's disease patients. Aging Clinical and Experimental Research. 2002; 14(5): 371-377. http://dx.doi.org/10.1007/BF03324464

[15] Martinez-Martin P, Benito-León J, Alonso F, et al. Quality of life of caregivers in Parkinson's disease. Quality of Life Research. 2005; 14(2): 463-472. PMid:15892435 http://dx.doi.org/10.1007/s11136-004-6253-y

[16] Goy ER, Carter JH, Ganzini L. Needs and experiences of caregivers for family members dying with Parkinson's disease. Journal of Palliative Care. 2008; 24(2): 69-75. PMid:18681242

[17] Batia S, Gupta A. Impairments in activities of daily living in Parkinson's disease: Implications for management. NeuroRehabilitation. 2003; 18(3):209-214.

[18] Martinez-Martin P, Arroyo S, Rojo-Abuin JM, Rodriguez-Blazquez C, Frades B, de Pedro Cuesta J. Burden, perceived health status, and mood among caregivers of Parkinson's disease patients. Movement Disorders. 2008; 23(12): 1673-1680. PMid:18709684 http://dx.doi.org/10.1002/mds.22106

[19] Goldsworthy B, Knowles S. Caregiving for Parkinson's disease patients: An exploration of a stress-appraisal model for quality of life and burden. Journals of Gerontology Series B: Psychological Sciences and Social Sciences. 2008; 63(6): 372-376. http://dx.doi.org/10.1093/geronb/63.6.P372

[20] Roland KP, Jenkins ME, Johnson AM. An exploration of the burden experienced by spousal caregivers of individuals with Parkinson's disease. Movement Disorders. 2010; 252(2): 189-213. PMid:20063397 http://dx.doi.org/10.1002/mds.22939 
[21] Shim B, Landerman LR, Davis LL. Correlates of care relationship mutuality among carers of people with Alzheimer's and Parkinson's disease. Journal of Advanced Nursing. 2011; 67(8): 1729-1738. PMid:21457292 http://dx.doi.org/10.1111/j.1365-2648.2011.05618.x

[22] Haberman B, Davis LL. Caring for family with Alzheimer's disease and Parkinson's disease. Needs, challenges, and satisfaction. Journal of Gerontological Nursing. 2005; 31(6): 49-54.

[23] Schrag A, Hovris A, Morley D, Quinn N, Jahanshahi M. Caregiver-burden in Parkinson's disease is closely associated with psychiatric symptoms, falls, and disability. Parkinsonism and Related Disorders. 2006; 12(1): 35-41. PMid:16271496 http://dx.doi.org/10.1016/j.parkreldis.2005.06.011

[24] Lőkk J. Caregiver strain in Parkinson disease and the impact of disease duration. European Journal of Physical Rehabilitation Medicine. 2008; 44(1): 39-45. PMid:18385627

[25] Figved N, Myhr KM, Larsen JP, Aarsland D. Caregiver burden in multiple sclerosis: The impact of neuropsychiatric symptoms. Journal of Neurology, Neurosurgery, and Psychiatry. 2007; 78(10): 1097-1102. PMid:17237144 http://dx.doi.org/10.1136/jnnp.2006.104216

[26] Davis LL, Gilliss CL, Deshefy-Longhi T, Chestnutt DH, Molloy M. The nature and scope of stressful spousal caregiving relationships. Journal of Family Nursing. 2011; 17(2): 224-240. PMid:21531858 http://dx.doi.org/10.1177/1074840711405666

[27] National Alliance for Caregiving. Caregivers of veterans serving on the homefront: Report of study findings [Internet]. 2010[Cited 2012 Aug.]. Available from http://www.caregiving.org/data/2010_Caregivers_of_Veterans_FULLREPORT_WEB_FINAL.pdf.

[28] Lai EC, Moore S. Demographics and distribution of Parkinson's disease/Parkinsonism by military period of service among veterans seen within the Veterans Affairs Healthcare System, FY 2002-2008. Neurology. 2011; 76: A124.

[29] United States Government Department of Veterans Affairs. Washington, DC: US Census and Population Projections. $2007: 85$.

[30] United States Government Department of Veteran Affairs. Washington, DC: Demographics: US Veterans [Internet]. 2009[cited 2011 Mar.]. Available from: www.veteranstoday.com/2009/03/16/demographics-u-s-veterans.

[31] United States Government Department of Veteran Affairs. Washington, DC: VA's Caregiver Support Program Expanding [Internet]. 2011[cited 2011 Mar.]. Available from: www.caregiver.va.gov/

[32] Selim AJ, Fincke BG, Ren XS, Lee A, Rogers WH, Miller DR, Kazis LE. Comorbidity assessments based on patient report: Results from the veterans health study. Ambulatory Care Management. 2004; 27(3): 281-295. http://dx.doi.org/10.1097/00004479-200407000-00011

[33] United States Government Department of Veterans Affairs. Washington, DC: The VA Parkinson Report[Internet]. 2013 [cited 2013 Dec.]. Available from: www/parkinsons.va.gov/Consortium/cfiles/Newletters/Summer 2013 National Newsletter.

[34] Gardner DG, Cummings, LL, Dunham RB, Pierce JL. Single-item versus multiple-item measurement scales: An empirical comparison. Educational and Psychological Measurement. 1998; 58: 898-915. http://dx.doi.org/10.1177/0013164498058006003

[35] Elo AL, Leppänen A, Jahkola A. Validity of a single-item measure of stress symptoms. Scandinavian Journal of Work and Environmental Health. 2003; 29(16): 444-451. http://dx.doi.org/10.5271/sjweh.752

[36] Zimmerman M, Ruggero CJ, Chelminski I. Developing brief scales for use in clinical practice: The reliability and validity of single-item self-report measures of depression symptom severity, psychosocial impairment due to depression and quality of life. Journal of Clinical Psychiatry. 2006; 67: 1536-1541. PMid:17107244 http://dx.doi.org/10.4088/JCP.v67n1007

[37] Field A. Discovering statistics using SPSS. 3rd ed. Chapter 8: Logistic regression, p. 264-300. Los Angeles: Sage.

[38] Yueh-Feng YL, Wykle M. Stress and self-care behaviors in response to symptoms. Clinical Nursing Research. 2007; 16(1): 29-43. PMid:17204806 http://dx.doi.org/10.1177/1054773806295238

[39] Coon DW, Evans B. Empirically based treatments for family caregiver distress: What works and where do we go from here? Geriatric Nursing. 2009; 30(6): 426-436. http://dx.doi.org/10.1016/j.gerinurse.2009.09.010 